\title{
Skłonność do tworzenia pęknięć zimnych złączy ze stali S420G2+M spawanej pod wodą metodą mokrą
}

\section{Susceptibility to cold cracking of underwater wet welded S420G2+M steel}

\section{Streszczenie}

Przeniesienie procesu spawania do środowiska wodnego skutkuje przede wszystkim zwiększeniem prędkości stygnięcia złącza oraz wzrostem zawartości wodoru dyfundującego w stopiwie. Środowisko wodne powoduje istotne pogorszenie spawalności stali jednak zastosowanie odpowiedniej technologii spawania pozwala na uzyskanie złączy o właściwościach zbliżonych do wykonywanych na powietrzu.

W pracy oceniono przydatność drobnoziarnistej stali po walcowaniu cieplno-mechanicznym na konstrukcje hydrotechniczne wymagające spawania podwodnego. $\mathrm{Na}$ podstawie wyników technologicznych prób spawalności stwierdzono, że złącza wykonane z niskowęglowej stali S420G2+M spawane w warunkach mokrych charakteryzują się częściową skłonnością do tworzenia pęknięć zimnych.
Abstract

The transfer of the welding process into the water environment results primarily in increasing the cooling rate of the weld and growth of diffusible hydrogen content in the deposited metal. The water environment causes significant deterioration of weldability of steel, however, an appropriate welding technology allows for obtaining joints with properties similar to those made in the air.

The current study assessed the usefulness of finegrained steel after thermo-mechanical rolling used for hydro-technical structures requiring the underwater welding. Results of weldability technological tests shown that joints of low carbon S420G2 + M steel welded under wet conditions are partly sensitive to cold cracking.

\section{Wstęp}

Spawanie pod woda jest najczęściej realizowane w warunkach bezpośredniego kontaktu z wodą (metodą mokrą) przy wykorzystaniu procesu spawania elektrodami otulonymi (111) [1-9]. Woda jako środowisko spawania stanowi źródło wodoru potencjalnego i powoduje wzrost prędkości stygnięcia złączy. Z tego powodu, w porównaniu do spawania w środowisku powietrznym, spawalność stali jest znacznie ograniczona przez wyższą skłonność do tworzenia pęknięć zimnych [1-4, 10]. Ponadto spawanie mokre prowadzone jest zazwyczaj

Dr inż. Dariusz Fydrych, dr inż. Grzegorz Rogalski, mgr inż. Jacek Tomków, dr hab. inż. Jerzy Łabanowski, prof. PG - Politechnika Gdańska. w warunkach ograniczonej widzialności i pogorszonej stabilności jarzenia się łuku, co również przyczynia się do powstawania niezgodności spawalniczych.

Środowisko eksploatacji konstrukcji przybrzeżnych oraz morskich wymusza stosowanie stali drobnoziarnistych o podwyższonej i wysokiej wytrzymałości, przy czym udział tych ostatnich może wynosić do $10 \%$ [11]. Pomimo coraz szerszego zastosowania wysokowytrzymałych stali drobnoziarnistych $w$ literaturze brakuje informacji o ich spawalności w warunkach podwodnych, co stanowi znaczne utrudnienie w przypadku konieczności przeprowadzenia napraw metodami spawalniczymi. Pewien pogląd na to zagadnienie mogą dać powszechnie dostępne wyniki badań spawalności stali drobnoziarnistych walcowanych cieplnomechanicznie wykonane w środowisku powietrznym. 
Spawalność tych stali jest lepsza niż stali normalizowanych o zbliżonej wytrzymałości (wartości granicy plastyczności), co wynika z niższej wartości równoważnika węgla [12, 13]. Daje to podstawy przypuszczeń, że stale po walcowaniu cieplno-mechanicznym będą harakteryzowały się zadowalającą spawalnością w przypadku spawania pod wodą. Hipoteza ta wymaga weryfikacji eksperymentalnej poprzez przeprowadzenie systematycznych badań spawalności różnych gatunków stali o granicy plastyczności w zakresie 355-500 MPa.

\section{Badania własne}

Celem badań było określenie skłonności do tworzenia pęknięć zimnych stali o podwyższonej wytrzymałości S420G2+M spawanej metodą mokrą elektrodami otulonymi. Badania zrealizowano wg następującego planu: [14]:

Wykonanie złączy próbnych wg PN-EN ISO 17642-2

- ze spoinami pachwinowymi (CTS) w środowisku powietrznym i wodnym,

- ze spoinami czołowymi (Tekken) w środowisku powietrznym i wodnym.

Badania złączy próbnych:

- badania wizualne (VT),

- badania penetracyjne (PT),

- badania metalograficzne makro- i mikroskopowe,

- pomiary twardości,

- oznaczenie ilości wodoru dyfundującego w stopiwie.
Do badań wykorzystana została stal konstrukcyjna S420G2+M wg PN-EN 10025-4 [15] o grubości 16 mm. Skład chemiczny stali oraz jej właściwości mechaniczne podano w tablicach I i II.

Złącza próbne zostały wykonane zgodnie z wymogami normy [14] na stanowisku do spawania pod wodą na głębokości $200 \mathrm{~mm}$ z wykorzystaniem elektrod otulonych o średnicy $4 \mathrm{~mm}$ :

- spoiny mocujące: elektrody o otulinie zasadowej EB 146 firmy ESAB (wszystkie próbki),

- spoiny próbne: komercyjne elektrody o otulinie rutylowej Omnia firmy Lincoln Electric oraz przeznaczone do spawania pod wodą elektrody o otulinie rutylowej Barracuda Gold firmy Speciality Welds.

Próbki oznaczono symbolami obejmującymi nazwę próby, litery: W (spawanie pod wodą) albo P (spawanie w środowisku powietrznym) i kolejny numer. Skład chemiczny elektrod użytych do wykonania spoin próbnych został przedstawiony w tablicy III. Parametry spawania próbek CTS i Tekken na powietrzu oraz pod wodą zestawiono w tablicach IV i V. Biegunowość spawania przyjęto zgodnie z zaleceniami producentów elektrod.

Badania wizualne i penetracyjne wszystkich złączy próbnych przeprowadzono zgodnie z zaleceniami norm [18-20] po upływie 72 godzin od zakończenia spawania. W badanych próbkach stwierdzono liczne podtopienia, przyklejenia, nierównomierności lica i rozpryski. Nie stwierdzono występowania pęknięć w złączach próbnych CTS wykonanych pod wodą, natomiast wykryto pękniecie w kraterze w próbce CTSP8. W próbkach Tekken podczas spawania w środowisku powietrznym pęknięcia w kraterze pojawiły się w spoinach wykonanych elektrodami Omnia oraz Barracuda. Podczas spawania podwodnego elektrodami Barracuda wykryto pęknięcia w osi spoiny.

Tablica I. Skład chemiczny stali S420G2+M

Table I. Chemical composition of S420G2+M steel

\begin{tabular}{|c|c|c|c|c|c|c|c|c|c|c|c|c|c|}
\hline & \multicolumn{12}{|c|}{ Zawartość pierwiastka, \% wag. } & \multirow[b]{2}{*}{$\mathrm{Ce}_{\mathrm{MIS}}$} \\
\hline & C & $\mathrm{Si}$ & $\mathrm{Mn}$ & $\mathrm{P}$ & $S$ & $\mathrm{Cr}$ & Mo & $\mathrm{Ni}$ & $\mathrm{Al}$ & $\mathrm{Cu}$ & $\mathrm{Ti}$ & $\mathrm{B}$ & \\
\hline * & 0,11 & 0,46 & 1,38 & 0,014 & 0,004 & 0,03 & - & 0,01 & 0,04 & 0,00 & 0,005 & 0,001 & 0,35 \\
\hline ** & 0,10 & 0,44 & 1,57 & 0,012 & 0,000 & 0,03 & - & 0,03 & 0,04 & 0,01 & 0,003 & 0,002 & 0,37 \\
\hline
\end{tabular}

Tablica II. Właściwości mechaniczne badanej stali S420G2+M wg atestu wytwórcy

Table II. Mechanical properties of S420G2+M steel

\begin{tabular}{|c|c|c|}
\hline $\mathrm{R}_{\mathrm{e}}, \mathrm{MPa}$ & $\mathrm{R}_{\mathrm{m}}, \mathrm{MPa}$ & $\mathrm{A}, \%$ \\
\hline 520 & 612 & 27,1 \\
\hline
\end{tabular}

Tablica III. Skład chemiczny elektrod, \% wag. [16, 17]

Table III. Chemical composition of electrodes, wt.\% $[16,17]$

\begin{tabular}{|c|c|c|c|c|c|c|c|c|c|c|}
\hline Elektroda & Rodzaj otuliny & $\mathrm{C}$ & $\mathrm{Si}$ & $\mathrm{Mn}$ & $P$ & S & $\mathrm{Cr}$ & $\mathrm{Cu}$ & $\mathrm{Nb}$ & $\mathrm{Ti}$ \\
\hline Omnia & Rutylowa & 0,07 & 0,5 & 0,5 & - & - & - & - & - & - \\
\hline Barracuda & Rutylowa & 0,04 & 0,23 & 0,34 & 0,017 & 0,008 & 0,02 & 0,016 & 0,02 & 0,017 \\
\hline
\end{tabular}


Tablica IV. Parametry spawania próbek CTS

Table IV. Conditions of CTS tests

\begin{tabular}{|c|c|c|c|c|c|c|c|}
\hline Nr. Próbki & Elektroda & Środowisko & Biegunowość & $\begin{array}{l}\text { Natężenie } \\
\text { prądu I, A }\end{array}$ & $\begin{array}{l}\text { Napięcie } \\
\text { łuku U, V }\end{array}$ & $\begin{array}{c}\text { Czas spawania } \\
\text { t, s }\end{array}$ & $\begin{array}{c}\text { Energia liniowa } \\
\text { spawania q, kJ/ } \\
\text { mm }\end{array}$ \\
\hline CTSP7 & Omnia & powietrze & dodatnia & 152 & 23 & 23,2 & 1,54 \\
\hline CTSP8 & Omnia & powietrze & dodatnia & 148 & 24 & 18,6 & 1,26 \\
\hline CTSP11 & Barracuda & powietrze & ujemna & 177 & 28 & 24,8 & 2,38 \\
\hline CTSP12 & Barracuda & powietrze & ujemna & 178 & 27 & 22,2 & 2,03 \\
\hline CTSW9 & Omnia & woda & dodatnia & 184 & 24 & 10 & 0,82 \\
\hline CTSW10 & Omnia & woda & dodatnia & 188 & 25 & 11,3 & 1,02 \\
\hline CTSW11 & Omnia & woda & dodatnia & 176 & 28 & 11 & 1,06 \\
\hline CTSW12 & Omnia & woda & dodatnia & 184 & 27 & 14,3 & 1,35 \\
\hline CTSW17 & Barracuda & woda & ujemna & 184 & 26 & 15 & 1,38 \\
\hline CTSW18 & Barracuda & woda & ujemna & 184 & 27 & 10,2 & 0,97 \\
\hline CTSW19 & Barracuda & woda & ujemna & 184 & 26 & 16 & 1,47 \\
\hline CTSW20 & Barracuda & woda & ujemna & 184 & 27 & 13,8 & 1,31 \\
\hline
\end{tabular}

Tablica V. Parametry spawania próbek Tekken

Table V. Conditions of Tekken tests

\begin{tabular}{|c|c|c|c|c|c|c|c|}
\hline Nr próbki & Elektroda & Środowisko & $\begin{array}{l}\text { Bieguno- } \\
\text { wość }\end{array}$ & $\begin{array}{l}\text { Natężenie } \\
\text { prądu I, A }\end{array}$ & $\begin{array}{l}\text { Napięcie } \\
\text { łuku U, V }\end{array}$ & $\begin{array}{c}\text { Czas } \\
\text { spawania } \\
\text { t, s }\end{array}$ & $\begin{array}{c}\text { Energia liniowa } \\
\text { spawania q } \\
\text { kJ/mm }\end{array}$ \\
\hline $\begin{array}{l}\text { Tekken } \\
\text { P7, P8 }\end{array}$ & Omnia & powietrze & dodatnia & 148 & 21 & 21 & 1,16 \\
\hline $\begin{array}{c}\text { Tekken } \\
\text { P11, P12 }\end{array}$ & Barracuda & powietrze & ujemna & 178 & 29 & 19,8 & 1,81 \\
\hline $\begin{array}{l}\text { Tekken } \\
\text { W8 }\end{array}$ & Omnia & woda & dodatnia & 184 & 26 & 16,3 & 1,38 \\
\hline $\begin{array}{c}\text { Tekken } \\
\text { W9, W10 }\end{array}$ & Omnia & woda & dodatnia & 184 & 25,8 & 21,4 & 1,80 \\
\hline $\begin{array}{c}\text { Tekken } \\
\text { W11, W12 }\end{array}$ & Barracuda & woda & ujemna & 184 & 27,8 & 13,2 & 1,20 \\
\hline $\begin{array}{c}\text { Tekken } \\
\text { W13, W14 }\end{array}$ & Barracuda & woda & ujemna & 184 & 26,5 & 14,8 & 1,28 \\
\hline
\end{tabular}

\section{Badania metalograficzne makroskopowe}

Badania metalograficzne makroskopowe przeprowadzono zgodnie z wytycznymi normy [21]. Przykładowe fotografie przekrojów złączy spawanych wykonanych pod wodą przedstawiono na rysunku 1 . Wyniki badań makroskopowych w większości potwierdziły wyniki badań wizualnych i penetracyjnych ujawniając ponadto występowanie wewnętrznych niezgodności spawalniczych, takich jak pęcherze i pęknięcia zainicjowane w grani.

\section{Badania metalograficzne mikroskopowe}

Badania metalograficzne mikroskopowe wykonano według normy [21]. Na rysunku 2 przedstawiono typową budowę strukturalną obszarów złączy spawanych $z$ badanej stali wykonanych w warunkach mokrych. W materiale rodzimym stali obserwowano drobnoziarnistą strukturę złożoną z ferrytu i niewielkim udziałem struktury perlitycznej. Występowały ziarna ferrytu o zróżnicowanej wielkości 3-10 $\mu \mathrm{m}$, natomiast ziarna perlitu układały się pasmowo zgodnie z kierunkiem 

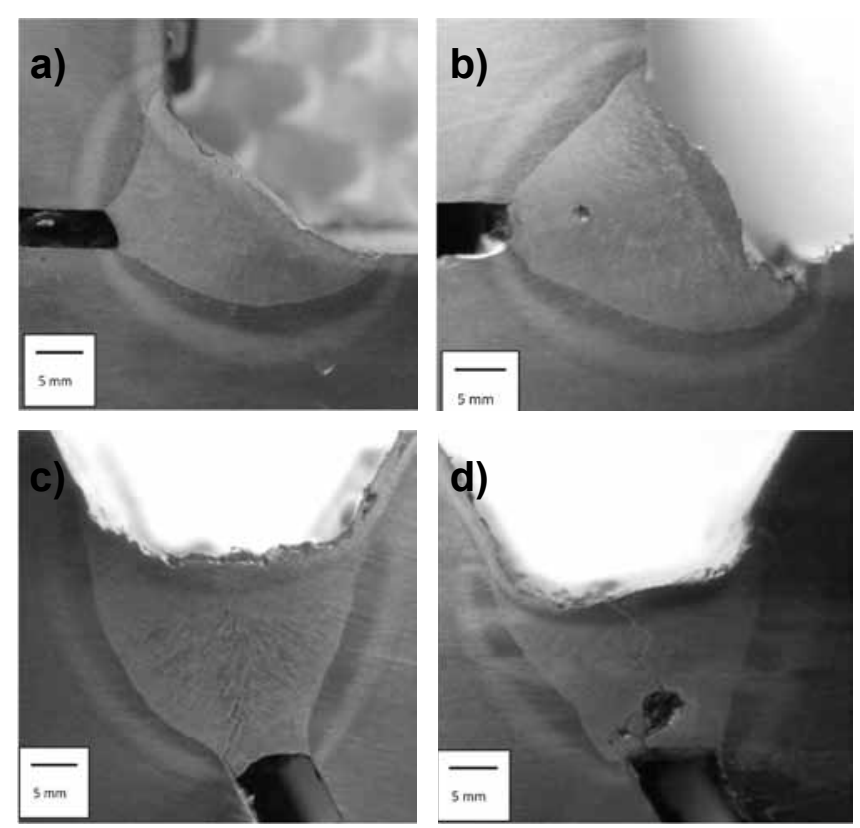

Rys. 1. Przekroje poprzeczne złączy próbnych wykonanych pod wodą: a) CTSW10 (elektroda Omnia). Widoczny pęcherz gazowy; b) CTSW17 (elektroda Barracuda). Brak niezgodności spawalniczych; c) TekkenW8 (elektroda Omnia). Widoczne pęknięcie w spoinie zainicjowane w grani; d) TekkenW13 (elektroda Barracuda). Widoczne pęknięcie w spoinie zainicjowane w grani oraz pęcherz gazowy. Traw. Nital

Fig. 1. Cross sections of test joints made under water: a) CTSW10 (electrode Omnia). Visible single pore; b) CTSW17 (electrode Barracuda). There are no imperfections; c) TekkenW8 (electrode Omnia). Visible crack in the weld initiated in the root; d) TekkenW13 (electrode Barracuda). Visible crack initiated in the root and large pore. Etch. Nital
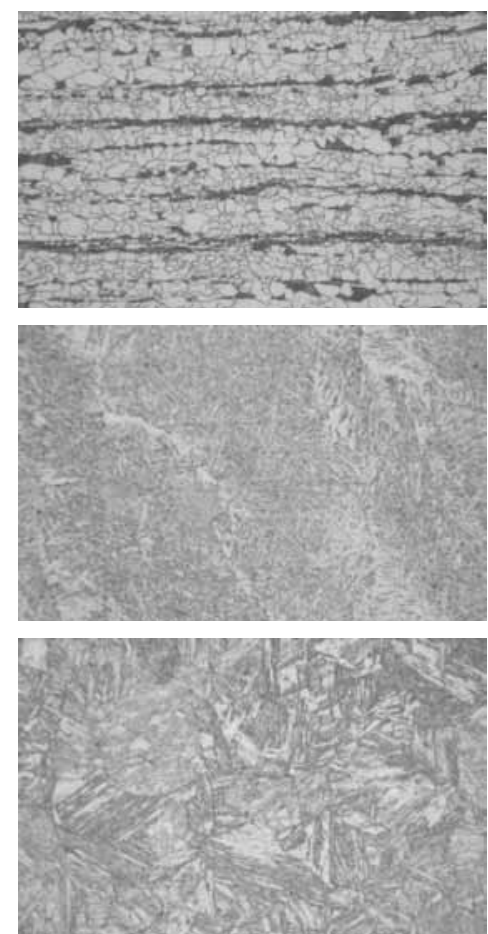

Rys. 2. Mikrostruktura złącza ze stali S420G2+M wykonanego pod woda; a) materiał rodzimy, b) spoina (elektroda Omnia), c) SWC obszar przegrzania. Pow. 200x

Fig. 2. Microstructure of S420G2+M steel joint welded under water; a) base material, b) weld (Omnia electrode), c) overheated zone in HAZ. Magn. 200x walcowania. Struktura spoiny składa się z ferrytu w układzie kolumnowym. W obszarze przegrzania SWC wyraźnie zaznaczone są granice byłego austenitu na tle których widoczny jest quasiperlit oraz iglaste struktury hartowania. Podczas obserwacji mikroskopowych przy powiększeniu 200x nie wykryto pęknięć w badanych obszarach próbek spawanych zarówno na powietrzu, jak i pod wodą.

\section{Pomiary twardości}

Pomiary twardości przeprowadzono zgodnie z normą [22] sposobem Vickersa przy obciążeniu $98 \mathrm{~N}$ (HV10) w linii przebiegającej $2 \mathrm{~mm}$ poniżej lica spoin próbnych. Przykładowe rozkłady twardości na przekrojach złączy spawanych pokazano na rysunkach 3 i 4. W tablicy VI zestawiono wyniki pomiarów w postaci twardości maksymalnych SWC badanych złączy.

Twardości maksymalne w SWC złączy próbnych CTS nie przekraczały wartości granicznej 380 HV10

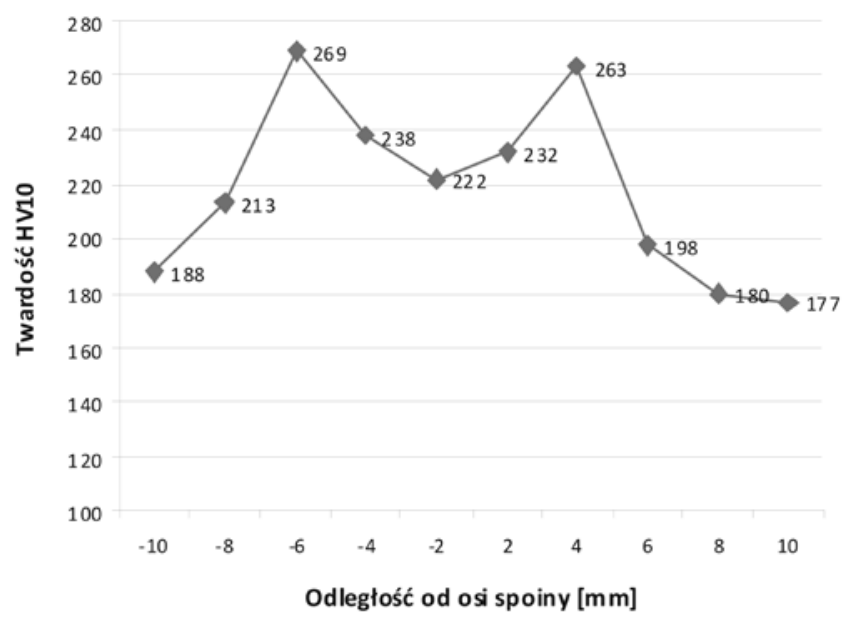

Rys. 3. Rozkład twardości złącza próbki TekkenP8, spawanej na powietrzu

Fig. 3. Hardness distribution across TekkenP8 joint welded at the air

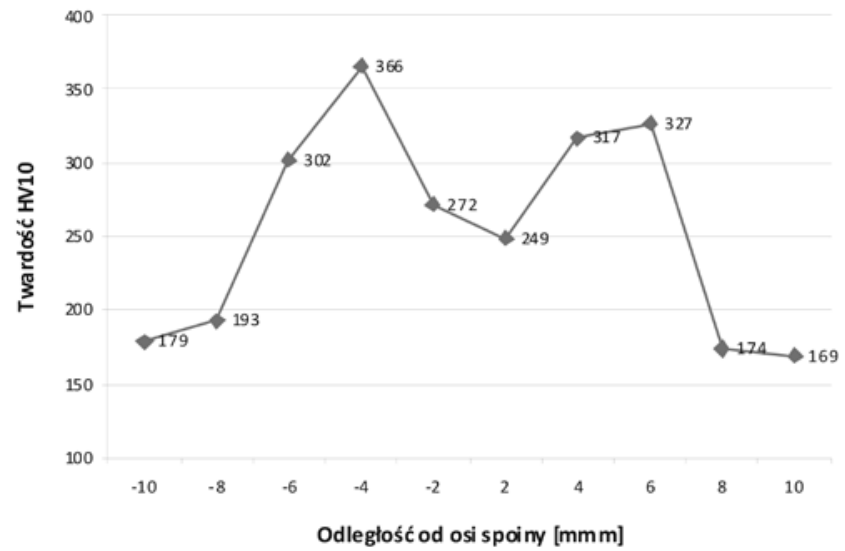

Rys. 4. Rozkład twardości złącza próbki TekkenW10 spawanej pod woda

Fig. 4. Hardness distribution across TekkenW10 joint welded under water 
Tablica VI. Wyniki pomiarów twardości

Table VI. Results of hardness tests

\begin{tabular}{|c|c|c|c|}
\hline Próba & elektroda & Środowisko wodne, $\mathrm{HV} 10_{\max }$ & Środowisko powietrzne, $\mathrm{HV} 10_{\max }$ \\
\hline \multirow{2}{*}{ CTS } & Omnia & 333 & 314 \\
\hline & Barracuda & 376 & 278 \\
\hline \multirow{2}{*}{ Tekken } & Omnia & 366 & 269 \\
\hline & Barracuda & 405 & 287 \\
\hline
\end{tabular}

przy spawaniu na powietrzu pod wodą. Natomiast w przypadku próbek Tekken w złączach wykonanych pod wodą stwierdzono w linii wtopienia wartości wyższe od 380 HV10. Różnica twardości maksymalnych wszystkich próbek Tekken i CTS wykonanych elektrodami Barracuda odnotowana po spawaniu w różnych środowiskach wynosiła ok. 100 HV10.

\section{Oznaczenie ilości wodoru dyfundującego w stopiwie}

Ilość wodoru dyfundującego w stopiwie użytych elektrod uzyskanym w środowisku wodnym i powietrznym oznaczono metodą glicerynową [9]. Wyniki w postaci średniej z trzech pomiarów przedstawiono w tablicy 7 . Stwierdzone zawartości wodoru dyfundującego w stopiwie próbek spawanych na powietrzu i pod wodą są charakterystyczne dla elektrod o otulinie rutylowej (odpowiednio zakresy od 30 do 50 i od 40 do $100 \mathrm{ml} / 100 \mathrm{~g}$ Fe) $[10,13]$. W rozważanym przypadku spawanie w środowisku wodnym spowodowało tylko nieznaczne zwiększenie ilości wodoru dyfundującego w stopiwie - do poziomu ok. $55 \mathrm{ml} / 100 \mathrm{~g} \mathrm{Fe}$.
Tablica VII. Wyniki pomiarów ilości wodoru dyfundującego w stopiwie Table VII. Results of determination of diffusible hydrogen content in deposited metal

\begin{tabular}{|l|c|c|}
\hline Gatunek elektrody & $\begin{array}{c}\text { Środowisko } \\
\text { wodne } \\
\mathrm{H}_{\mathrm{D}}, \mathrm{ml} / 100 \mathrm{~g} \mathrm{Fe}\end{array}$ & $\begin{array}{c}\text { Środowisko po- } \\
\text { wietrzne } \\
\mathrm{H}_{\mathrm{D}}, \mathrm{ml} / 100 \mathrm{~g} \mathrm{Fe}\end{array}$ \\
\hline Omnia & 52,8 & 35,1 \\
\hline Barracuda & 55,6 & 48,5 \\
\hline
\end{tabular}

\section{Podsumowanie}

W pracy określono skłonność do tworzenia pęknięć zimnych złączy spawanych ze stali S420G2+M w aspekcie potencjalnej możliwości przeprowadzania napraw konstrukcji hydrotechnicznych. Na podstawie wyników badań złączy próbnych typu CTS i Tekken (tablice VIII i IX) wykonanych przy użyciu dwóch gatunków elektrod otulonych: Omnia i Barracuda stwierdzono, że w przypadku spawania w środowisku powietrznym badana stal jest dobrze spawalna zarówno w przypadku wykonywania spoin pachwinowych, jak i czołowych. Jednak podczas jej spawania pod wodą dla złączy doczołowych następuje wzrost skłonności do tworzenia

Tablica VIII. Wyniki badań złączy CTS

Table VIII. Results of investigations of CTS joints

\begin{tabular}{|c|c|c|c|c|c|}
\hline Nr próbki & Środowisko & Elektroda & $\begin{array}{c}\mathrm{H}_{\mathrm{Dśr}} \mathrm{ml} / 100 \mathrm{~g} \\
\mathrm{Fe}\end{array}$ & $\begin{array}{c}\text { Badania nieniszczące } \\
\text { (VT i PT) }\end{array}$ & $\begin{array}{c}\text { Badania metalograficz- } \\
\text { ne }\end{array}$ \\
\hline CTSP7 & powietrze & Omnia & \multirow{2}{*}{35,1} & brak pęknięć & brak pęknięć \\
\hline CTSP8 & powietrze & Omnia & & pęknięcie w kraterze & brak pęknięć \\
\hline CTSP11 & powietrze & Barracuda & \multirow{2}{*}{48,5} & brak pęknięć & brak pęknięć \\
\hline CTSP12 & powietrze & Barracuda & & brak pęknięć & brak pęknięć \\
\hline CTSW9 & woda & Omnia & \multirow{4}{*}{52,8} & brak pęknięć & brak pęknięć \\
\hline CTSW10 & woda & Omnia & & brak pęknięć & brak pęknięć \\
\hline CTSW11 & woda & Omnia & & brak pęknięć & brak pęknięć \\
\hline CTSW12 & woda & Omnia & & brak pęknięć & brak pęknięć \\
\hline CTSW17 & woda & Barracuda & \multirow{4}{*}{55,6} & brak pęknięć & brak pęknięć \\
\hline CTSW18 & woda & Barracuda & & brak pęknięć & brak pęknięć \\
\hline CTSW19 & woda & Barracuda & & brak pęknięć & brak pęknięć \\
\hline CTSW20 & woda & Barracuda & & brak pęknięć & brak pęknięć \\
\hline
\end{tabular}


Tablica IX. Wyniki badań złączy Tekken

Table IX. Results of investigations of Tekken joints

\begin{tabular}{|c|c|c|c|c|c|}
\hline Nr próbki & Środowisko & Elektroda & $\mathrm{H}_{\mathrm{Dśr}}, \mathrm{ml} / 100 \mathrm{~g} \mathrm{Fe}$ & Badania nieniszczące (VT i PT) & Badania metalograficzne \\
\hline $\begin{array}{l}\text { Tekken } \\
\text { P7, P8 }\end{array}$ & powietrze & Omnia & 35,1 & pęknięcie w kraterze & brak pęknięć \\
\hline $\begin{array}{c}\text { Tekken } \\
\text { P11, P12 }\end{array}$ & powietrze & Barracuda & 48,5 & pęknięcie w kraterze & brak pęknięć \\
\hline $\begin{array}{l}\text { Tekken } \\
\text { W8 }\end{array}$ & woda & Omnia & \multirow{2}{*}{52,8} & brak pęknięć & pęknięcie \\
\hline $\begin{array}{c}\text { Tekken } \\
\text { W9, W10 }\end{array}$ & woda & Omnia & & brak pęknięć & brak pęknięć \\
\hline $\begin{array}{c}\text { Tekken } \\
\text { W11, W12 }\end{array}$ & woda & Barracuda & \multirow{2}{*}{55,6} & pęknięcie & pęknięcie \\
\hline $\begin{array}{c}\text { Tekken } \\
\text { W13, W14 }\end{array}$ & woda & Barracuda & & pęknięcie & pęknięcie \\
\hline
\end{tabular}

pęknięć zimnych w spoinie do poziomu skłonności częściowej. Zweryfikowanie dokonanej oceny spawalności wymaga przeprowadzenia badań metodą ilościową, np. próbą implant wg normy [23].

Pęknięcia zimne pojawiły się w spoinach, natomiast wolna od nich była SWC. Zjawisko to jest charakterystyczne dla stali po obróbce cieplno-mechanicznej $[12,13]$.

W SWC próbek Tekken i CTS występowały struktury hartowania charakterystyczne dla złączy wykonywanych w warunkach dużej prędkości stygnięcia, jednak obecności pęknięć w tej strefie nie wykryto.

Analiza rozkładów twardości złączy próbnych wykazała, że wzrost prędkości stygnięcia spowodowany przeniesieniem spawania pod powierzchnię wody był przyczyną wzrostu twardości maksymalnej o ok. 100 HV10, a pomierzone wartości znajdują się w zakresie 333-405 HV10 (tablica VI). W przypadku przyjęcia za kryterium akceptacji wymagań PN-EN ISO 15614-1
(380 HV10 dla badanej stali) wszystkie badane złącza, z wyjątkiem próbek Tekken wykonanych elektrodami Barracuda pod wodą, je spełniają [24].

Oznaczone metoda glicerynową zawartości wodoru dyfundującego w stopiwie zgodnie $z$ oczekiwaniami kwalifikują wszystkie przeprowadzone badania do wysokowodorowych procesów spawalniczych. Zmniejszenie stopnia nawodorowania próbek $w$ ograniczonym zakresie można osiągnąć poprzez zmiany parametrów spawania $[9,10]$.

W praktyce większość podwodnych prac spawalniczych wykonuje się z zastosowaniem spoin pachwinowych, więc otrzymane wyniki są obiecujące w odniesieniu do realizacji napraw konstrukcji pracujących pod wodą. Ponieważ efektywną metodą poprawy spawalności stali w warunkach spawania podwodnego może być zastosowanie techniki ściegu odpuszczającego, dalsze badania powinny być ukierunkowane na zweryfikowanie skuteczności tej technologii [25].

\section{Wnioski}

1. Na podstawie wyników technologicznych prób spawalności niskowęglowej stali drobnoziarnistej gatunku S420G2+M można stwierdzić, że:

- złącza CTS wykonane elektrodami otulonymi na powietrzu i pod wodą w warunkach mokrych charakteryzują się zadowalająca spawalnością,

- złącza Tekken wykonane elektrodami otulonymi na powietrzu charakteryzują się zadowalająca spawalnością, jednak przeniesienie procesu pod wodę spowodowało wzrost skłonności do tworzenia pęknięć zimnych w spoinie, co dało podstawy do oceny tej skłonności jako częściowej.

2. Przeniesienie spawania pod wodę było przyczyną wzrostu twardości maksymalnej w SWC o ok. 100

HV10, jednak w większości przypadków złącza próbne spełniają kryterium akceptacji wymagań wg normy PN-EN ISO 15614-1.

3. Wyniki pomiarów zawartości wodoru dyfundującego w stopiwie uzyskane w środowisku powietrznym i wodnym są typowe dla zastosowanych elektrod o otulinie rutylowej, również $w$ aspekcie wzrostu stężenia wodoru w próbkach wykonanych pod wodą.

4. Dalsze badania powinny być ukierunkowane na zweryfikowanie pozytywnego wpływu spawania wielościegowego na spawalność badanej stali. 


\section{Literatura}

[1] AWS D3.6M:2010 Underwater Welding Code.

[2] Łabanowski J., Fydrych D., Rogalski G.: Underwater WeIding - a review. Advances in Materials Science, 3/2008.

[3] Cotton H. C.: Welding under water and in the splash zone -a review. Proceedings of the International Conference „Underwater Welding", Trondheim, Norway 1983.

[4] Maksimov S. Yu.: Underwater arc welding of higher strength low-alloy steels. Welding International Vol. 24, Iss. 6, June 2010, p. 449-454.

[5] Rodriguez-Sanchez J. E., Rodriguez-Castellanos A., PerezGuerrero F., Carbajal-Romero M. F., Liu S.: Offshore fatigue crack repair by grinding and wet welding. Fatigue and Fracture of Engineering Materials and Structures, 34/2010.

[6] Pessoa E., Bracarense A., Zica E., Liu S., Perez-Guerrero F.: Porosity variation along multi-pass underwater wet welds and its influence on mechanical properties. Journal of Materials Processing Technology. Vol. 179, Issues 1-3, 20 October 2006, pp. 239-243.

[7] Liu D., Zhang H., Yang K., Tang D., Feng J.: Microstructure evolution of HAZ in the multi-pass underwater wet welded joints. China Welding Vol. 22, no. 1, 2013, p. 30-34.

[8] Fydrych D., Łabanowski J., Rogalski G.: Weldability of high strength steels in wet welding conditions. Polish Maritime Research Vol. 20, Iss. 2, 2013, p. 67-73.

[9] Fydrych D., Rogalski G.: Effect of shielded-electrode wet weIding conditions on diffusion hydrogen content in deposited metal. Welding International Vol. 25, Iss. 3, March 2011, p. 166-171.

[10] Fydrych D.: Pękanie zimne stali spawanej w środowisku wodnym. Przeglad Spawalnictwa 10/2012.

[11] Ćwiek J.: Niszczenie wodorowe stali spawalnych o wysokiej wytrzymałości. Wydawnictwo Politechniki Gdańskiej, Gdańsk 2006

[12] Brózda J.: Stale konstrukcyjne i ich spawalność. Instytut Spawalnictwa. Gliwice 2009.
[13] Tasak E.: Spawalność stali. Wydawnictwo Fotobit. Kraków 2002.

[14] PN-EN ISO 17642-2:2005 Spawalnictwo. Badania niszczace spoin w metalach. Badania pękania na zimno złączy spawanych. Metody spawania łukowego. Cześć 2 : Próby z utwierdzeniem własnym.

[15] PN-EN 10025-4:2007 Wyroby walcowane na goraco ze stali konstrukcyjnych. Część 4: Warunki techniczne dostawy spawalnych stali konstrukcyjnych drobnoziarnistych po walcowaniu termomechanicznym.

[16] http://www.lincolnelectric.com/

[17] http://www.specialwelds.com/

[18] PN-EN ISO 17637:2011 Badania nieniszczące złączy spawanych. Badania wizualne złączy spawanych.

[19] PN-EN 571-1:1999 Badania nieniszczące. Badania penetracyjne. Zasady ogólne.

[20] PN-EN ISO 23277:2010 Badanie nieniszczące spoin. Badanie penetracyjne spoin. Poziomy akceptacji.

[21] PN-EN 1321:2000 Spawalnictwo. Badania niszczące metalowych złączy spawanych. Badania makroskopowe i mikroskopowe złączy spawanych.

[22] PN-EN 1043-1:2000 Spawalnictwo. Badania niszczące metalowych złączy spawanych. Próba twardości. Próba twardości złączy spawanych łukowo.

[23] PN-EN ISO 15614-1:2008 Specyfikacja i kwalifikowanie technologii spawania metali. Badanie technologii spawania. Część 1: Spawanie łukowe i gazowe stali oraz spawanie łukowe niklu i stopów niklu.

[24] PN-EN ISO 17642-3:2005 Spawalnictwo. Badania niszczace spoin w metalach. Badania pękania na zimno złączy spawanych. Metody spawania łukowego. Cześć 3: Badania z obciążeniem zewnętrznym.

[25] Fydrych D., Łabanowski J.: Zastosowanie techniki ściegu odpuszczającego do spawania mokrego. Przegląd Spawalnictwa 2/2013.

\section{PLANY SPAWANIA - TEORIA I PRAKTYKA - JACEK SLANIA}

\section{Cena}

Cena 1 egzemplarza książki Jacka Słani: Plany spawania - teoria i praktyka 80 zł (w tym 5\% VAT)

W celu zamówienia książki w Redakcji należy wypełnić formularz zamieszczony obok i przesłać go w formie faksu, skanu lub listu na adres:

\section{REDAKCJA - Przegląd Spawalnictwa AW SIMP}

ul. Świętokrzyska 14a, 00-050 Warszawa

tel.: 2282725 42, faks: 223361479 e-mail: pspaw@ps.pl

Wpłaty należy dokonać na rachunek bankowy Bank BPH S.A. Oddział w Warszawie 45106000760000320000431836

\section{Zamawiam książkę Plany spawania - teoria i praktyka} w Redakcji Przegląd Spawalnictwa w ilości .... egz.

Imię i nazwisko

Firma

Adres

NIP

Kontakt do osoby zamawiającej:

Oświadczam, że jestem podatnikiem VAT i upoważniam firmę do wystawienia faktury bez podpisu 